\title{
Antigens involved in resistance to mucosal association by Vibrio cholerae
}

\author{
R. NARENDRANATHAN, L. H. LUTZE, G. D. F. JACKSON and G. N. COOPER*
}

School of Microbiology, University of New South Wales, PO Box 1, Kensington 2033, NSW, Australia

\begin{abstract}
Summary. Resistance to growth of Vibrio cholerae at the mucosa of blind intestinal loops developed in rats after intestinal or parenteral exposure to live organisms or other antigenic materials. Simultaneous serological studies suggested that neither serum vibriocidal activity nor intestinal mucus antibodies are likely to provide a direct test of antibacterial immune status. Challenge of rats 4 weeks after one dose of antigen may reveal a form of immunity that is not related to antibodies in the intestine and possibly is analogous to long-term immunity expressed in man following infection with the organism. This immunity has not been attributed to lipopolysaccharide (LPS) antigen and does not appear to involve flagella-associated antigens; involvement of antigens other than LPS, such as protein antigens of the outer membranes of $V$. cholerae, has not yet been substantiated. Separation of monomeric sub-units of outermembrane proteins by hydrophobic interaction high pressure liquid chromatography has revealed significant quantitative differences among preparations derived from the common serotypes of the organism. These differences may be sufficient to explain the better protection observed when homologous serotypes were used for immunisation and challenge in the long-term resistance model.
\end{abstract}

\section{Introduction}

Because it seems likely that antibacterial immune mechanisms prevent intestinal colonisation by Vibrio cholerae (Levine et al., 1979), a method for quantifying its association with the intestinal mucus blanket of rats has been adapted recently to investigate the development and nature of this immunity (Cooper and Narendranathan, 1986). The efficacies of several different vaccines and immunising regimens were compared to assess the discriminatory potential of the method. Evidence suggested that, among other things, resistance to mucosal colonisation was induced by local (intestinal) immunisation, that it was not serotype specific, and that it correlated best with the presence of serum vibriocidal antibodies rather than with antibodies directed against the lipopolysaccharide or serologically dominant outer-membrane protein antigens of $V$. cholerae. The latter results, however, did not exclude a protective role for these antigens. The experiments reported here examined additional aspects of immunity to mucosal colonisation and questioned further the protective capacities of the major surface antigens of $V$. cholerae.

Received 9 Feb. 1987; revised version accepted 15 May 1987.

* Correspondence should be sent to Professor G. N. Cooper.

\section{Materials and methods}

\section{Bacterial strains}

Methods for preservation, culture and preparation of suspensions of $V$. cholerae strains have been described previously (Cooper and Narendranathan, 1986). Biotype, serotype and other characteristics as well as sources of these strains are described (see table III). Pseudomonas aeruginosa strain NSW467 and a recent isolate of Campylobacter jejuni were obtained from our culture collection.

\section{Animals}

Adult Wistar strain rats of either sex were used; they were 60-90 days old.

\section{Immunisation}

Methods for intra-intestinal (i.i.) and intra-Peyer's patch (i.p.p.) injection of bacterial suspensions into rats have been described elsewhere (Cooper and Narendranathan, 1986). When used, antigen preparations (vide infra) were suspended $(3 \mathrm{mg} / \mathrm{ml})$ in $0.1 \mathrm{M}$ phosphatebuffered ( $p \mathrm{H} 7 \cdot 0)$ saline (PBS) homogenised with equal volumes of Freund's complete adjuvant (Commonwealth Serum Laboratories, Victoria, Australia) for Peyer's patch immunisation. In some instances, bacterial suspensions were given intravenously (i.v.) in a tail vein. 


\section{Antigens of $V$. cholerae}

Lipopolysaccharide (LPS) was prepared by the method of Westphal and Jann (1965) from 24-h cultures grown on Tryptose Soya Agar (TSA, Oxoid) at $37^{\circ} \mathrm{C}$.

Outer-membrane proteins (OMPs) were prepared from cultures grown on TSA for $40 \mathrm{~h}$ at $37^{\circ} \mathrm{C}$. The organisms were harvested, washed once and suspended ( $1 g$ wet wt/ $40 \mathrm{ml}$ ) in $10 \mathrm{~mm}$ Tris- $\mathrm{HCl}$ (Sigma) buffer $(p \mathrm{H} 8)$ containing sucrose $15 \% \mathrm{w} / \mathrm{v}$ and $10 \mathrm{~mm} \mathrm{Na}{ }_{2}$ EDTA (Ajax Chemicals, Sydney, Australia). Lysozyme $(0.5 \mathrm{mg} / \mathrm{ml})$ was added and after incubation for $30 \mathrm{~min}$ at $20^{\circ} \mathrm{C}$ the suspension, chilled on ice, was sonicated for $60 \mathrm{sec}$. Unbroken cells were removed by centrifugation at $5000 \mathrm{~g}$ for $15 \mathrm{~min}$. Cell envelopes were recovered from the supernate by centrifugation at $48000 \mathrm{~g}$ for $30 \mathrm{~min}$. The pellet was suspended in 10 volumes of $10 \mathrm{mM}$ Tris- $\mathrm{HCl}$ buffer $(p \mathrm{H} \mathrm{7.8)}$ containing $10 \mathrm{mM} \mathrm{MgCl}_{2}$. Contaminating DNA was removed by treatment with DNAase (Sigma) $10 \mu \mathrm{g} / \mathrm{ml}$. Membranes were then collected by centrifugation at $48000 \mathrm{~g}$ for $30 \mathrm{~min}$. The inner membranes were removed by extraction with Triton X-100 (Schnaitman, 1971). The pellet was resuspended in 4 volumes of Triton X-100 in Tris- $\mathrm{MgCl}_{2}$, held at room temperature for $30 \mathrm{~min}$ and the outer membranes were collected by ultracentrifugation $\left(100000 \mathrm{~g}\right.$ for $60 \mathrm{~min}$ at $4^{\circ} \mathrm{C}$ ) and stored in PBS at $-20^{\circ} \mathrm{C}$.

\section{Sodium dodecyl sulphate-polyacrylamide gel electrophoresis (SDS-PAGE)}

Stacking gel $5 \% \mathrm{w} / \mathrm{v}$ and resolving gel $10 \% \mathrm{w} / \mathrm{v}$, containing methylene bisacrylamide $0.54 \% \mathrm{w} / \mathrm{v}$, were used in the system of Laemmli (1970). Gel dimensions were $150 \times 120 \times 0.75 \mathrm{~mm}$. Samples were solubilised by boiling for $3 \mathrm{~min}$ in an equal volume of sodium dodecyl sulphate (Sigma) $2 \% \mathrm{w} / \mathrm{v}$ in buffer $(62.5 \mathrm{mM}$ Tris-HCl) containing glycerol (BDH) $10 \% \mathrm{v} / \mathrm{v}$ and 2-mercaptoethanol (Sigma) $5 \% \mathrm{v} / \mathrm{v}$. Electrophoresis was performed at $30 \mathrm{~mA}$ per gel until a control dye band was $1 \mathrm{~cm}$ from the bottom $(c .4 \mathrm{~h})$. Gels were fixed overnight in methanolacetic acid-water $(10: 10: 80)$; protein bands were stained with Coomassie Blue R250 (Sigma) $0.01 \% \mathrm{w} / \mathrm{v}$ in fixing solution for $4 \mathrm{~h}$ and destained in several changes of isopropanol-acetic acid-water $(25: 10: 65)$.

\section{High performance liquid chromatography (HPLC)}

OMPs were solubilised (vide supra) and 250- $\mu \mathrm{g}$ samples separated by hydrophobic interaction on a $280 \times 5 \mathrm{~mm} \mu-$ Bondapak $\mathrm{C}_{18}$ column (Millipore-Waters, Sydney, Australia) that had been equilibrated in acetonitrile $10 \% \mathrm{v} / \mathrm{v}$ in water containing trifluoracetic acid (TFA) $0.1 \% \mathrm{v} / \mathrm{v}$. Proteins were eluted with a linear gradient over $15 \mathrm{~min}$ from 10 to $100 \%$ acetonitrile in TFA $0 \cdot 1 \% \mathrm{v} / \mathrm{v}$ followed by elution with acetonitrile containing TFA $0 \cdot 1 \% \mathrm{v} / \mathrm{v}$ for $10 \mathrm{~min}$. Elution was monitored by absorbance at $280 \mathrm{~nm}$. Retention times for each peak, area and relative abundances were calculated by a Data module connected to the absorbance monitor (Millipore-Waters).

\section{Immunoblotting}

OMPs separated by electrophoresis were transferred electrophoretically to nitrocellulose paper (Towbin et al., 1979) which was then incubated for $60 \mathrm{~min}$ at $37^{\circ} \mathrm{C}$ in $25 \mathrm{~mm}$ Tris- $\mathrm{HCl}$ buffer containing $0.5 \mathrm{M} \mathrm{NaCl}$ and bovine serum albumin $3 \% \mathrm{w} / \mathrm{v}$ (TBS). The separated proteins were then exposed for $2 \mathrm{~h}$ at $37^{\circ} \mathrm{C}$ to appropriate rabbit antisera diluted 1 in 50 in TBS. After washing in TBS, the paper was placed in a 1 in 2000 dilution of goat antirabbit IgG antiserum labelled with horse-radish peroxidase (Kirkegaarde and Perry Inc., Gaithersberg, MD, USA) for $4 \mathrm{~h}$ before washing in TBS. Labelled material was located by the method of Hawkes et al. (1982).

\section{Antisera}

A hyperimmune antiserum was prepared in rabbits by i.v. injection of live bacteria of $V$. cholerae strain BRL 7738 of Inaba serotype. The first dose contained $5 \times 10^{6} \mathrm{cfu}$; a further eight doses each increasing by 2 -fold were given at weekly intervals. Sera were collected one week after the last injection, decomplemented at $56^{\circ} \mathrm{C}$ for $30 \mathrm{~min}$, and stored at $-20^{\circ} \mathrm{C}$.

Antiserum raised against LPS of the same Inaba strain was also used. Rabbits were given intramuscular (i.m.) injections of $100-\mu \mathrm{g}$ doses of this antigen in Freund's complete adjuvant at 14-day intervals for 6 weeks; sera were prepared and stored as above.

\section{Absorption of sera with LPS}

Inaba LPS $(4 \mathrm{mg} / \mathrm{ml})$ was added to antiserum diluted 1 in 2 in PBS, incubated at $37^{\circ} \mathrm{C}$ for $2 \mathrm{~h}$, held overnight at $4^{\circ} \mathrm{C}$ and centrifuged at $100000 \mathrm{~g}$ for $2 \mathrm{~h}$ at $4^{\circ} \mathrm{C}$. This procedure was repeated three times. Absence of anti-LPS antibodies was confirmed by failure of the absorbed material to cause agglutination of sheep red-blood cells passively sensitised with homologous LPS by the method of Auzins (1968).

\section{Antibody measurements}

Serum vibriocidal antibody titres were determined as described by Cooper and Jackson (1981) with V. cholerae strain BRL7738 as antigen. ELISA methods for detecting antibodies to LPS of $V$. cholerae (anti-LPS) and the serologically dominant, heat-sensitive OMPs (antiHSSP) in serum and intestinal mucus have been reported elsewhere (Cooper et al.; 1984). For the latter, concentrations were expressed, on a scale from 0 to +++ , as increases in titres above those found in non-immunised rats; increases of $<4$-fold ( 0 in tables II, IV and V) were not considered significant. Though antibodies of the three major immunoglobulin classes may be detected, serum IgM and $\operatorname{IgG}$ and intestinal mucus $\operatorname{IgG}$ and $\operatorname{IgA}$ antibody levels only are reported herein as previous studies showed that these classes of immunoglobulins, respectively, best reflected systemic and local output of antibodies (Cooper et al., 1984). 


\section{Assessment of immunity to intestinal colonisation}

Methods for infecting blind intestinal loops with $V$. cholerae and enumerating mucosa-associated bacteria have been described before (Cooper and Narendranathan, 1986). Streptomycin-resistant mutants of the strains BRL7738 (El Tor, Inaba) and O162 (Classical, Ogawa) were used for challenge infection; $(2-5) \times 10^{3} \mathrm{cfu}$ were injected in each of the three or four loops prepared in each rat. The animals were killed by cervical dislocation under ether anaesthesia $14 \mathrm{~h}$ after inoculation; the loops were removed, opened longitudinally, washed vigorously in three changes of PBS, homogenised in $10 \mathrm{ml}$ of PBS with a Teflon grinder or, in some instances, an UltraTurrax homogeniser. The number of cfu's per loop was estimated by the standard loop dilution method of Schaedler et al. (1965).

\section{Mucosa-association resistance ( $M A R$ ) index}

This, the difference (in $\log _{10}$ units) between the mean cfu of mucosa-associated organisms in loops taken from non-immunised and immunised rats tested at the same time, was used to compare immunising regimens. Groups of four rats were used on each occasion and each experiment was repeated at least once. As the mean cfu of mucosa-associated organisms found in loops of immunised and normal rats on the two days of testing in each experiment were not significantly different $(p>0.2$ by Student's $t$ test) the MAR indices reported here were calculated from the means of at least 24 loops examined over 2 days. Student's $t$ test was used to determine the significance of the MAR indices; under normal circumstances MAR indices of $<2.0$ were not significant at the $1 \%$ level and were deemed to reflect little or no protection. Indices $>4.0$ were at the upper limits of measurement and suggested strong resistance to colonisation.

\section{Results}

\section{Duration of resistance to mucosal association}

Groups of rats were given one or two doses of live bacteria of $V$. cholerae strain 569B by the i.i. or i.v. routes. Immunity to mucosal association by $V$. cholerae strain BRL7738, serum vibriocidal antibody titres, intestinal mucus anti-LPS and antiHSSP antibody levels were determined at various times thereafter. The results shown in table I indicate that resistance developed within 2 weeks of one i.i. dose of organisms; immunity lasted from week 4 to week 12 but was lost by week 20 . When two doses of antigen were given 14 days apart, strong immunity was evident within one week and lasted for at least 20 weeks. Parenteral i.v. immunisation was also effective. Antibody levels in similarly immunised rats are shown in table II; though humoral responses were evident after one
Table I. Immunity to mucosal association by $V$. cholerae strain BRL7738 after immunisation of rats with live $V$. cholerae strain 569B

\begin{tabular}{|c|c|c|c|}
\hline \multirow[b]{2}{*}{$\begin{array}{c}\text { Number of } \\
\text { immunising } \\
\text { doses }\end{array}$} & \multirow[b]{2}{*}{$\begin{array}{l}\text { Time of challenge } \\
\text { (weeks after } \\
\text { last dose) }\end{array}$} & \multicolumn{2}{|c|}{$\begin{array}{l}\text { MAR indices* of rats } \\
\text { immunised }\end{array}$} \\
\hline & & $\begin{array}{l}\text { i.i. } \\
\left(c .1 \times 10^{9}\right. \\
\text { cfu/dose })\end{array}$ & $\begin{array}{l}\text { i.v. } \\
\left(c .1 \times 10^{8}\right. \\
\text { cfu/dose })\end{array}$ \\
\hline \multirow[t]{5}{*}{1} & 1 & $1.72(\mathrm{NS})$ & $1 \cdot 20(\mathrm{NS})$ \\
\hline & 2 & $3 \cdot 22(\mathrm{~S})$ & $3.95(\mathrm{~S})$ \\
\hline & 4 & $4 \cdot 58(S)$ & $4 \cdot 73(S)$ \\
\hline & 12 & $3.05(\mathrm{~S})$ & $3 \cdot 37(\mathrm{~S})$ \\
\hline & 20 & 1.60 (NS) & 1.71 (NS) \\
\hline \multirow[t]{3}{*}{$2 \dagger$} & 1 & $4.83(S)$ & $4.85(\mathrm{~S})$ \\
\hline & 12 & $4.90(\mathrm{~S})$ & $4.53(\mathrm{~S})$ \\
\hline & 20 & $2 \cdot 94$ (S) & 2.75 (S) \\
\hline
\end{tabular}

* Mucosa-association resistance index determined from mean numbers of organisms found in 24 loops prepared in groups of 8 rats.

$\dagger$ Doses given 14 days apart.

$\mathrm{S}=$ significant; and $\mathrm{NS}=$ not significant, at $5 \%$ level of Student's $t$ test.

and two injections, in some instances as long as 12 weeks after one dose, there was resistance to mucosal colonisation when antibody titres in serum and intestinal mucus were not significantly different from those found in non-immunised rats.

\section{Specificity of resistance to mucosa association}

Rats were given single i.i. doses of $c .1 \times 10^{9} \mathrm{cfu}$ of strains representing the common biotypes and serotypes of $V$. cholerae; these rats and nonimmunised rats were challenged 4 weeks later with strains BRL 7738 or O162. Differences in protective capacity provided by the different bacterial strains were evident (table III). In all but three instances, however, significant immunity to challenge by both strains was found. With 12 of the 15 strains tested, the MAR indices recorded for both challenge strains differed significantly and in all cases the higher resistance index was recorded for groups immunised and challenged with a strain of the homologous serotype. The strain of Hikojima serotype, which expresses both Inaba and Ogawa serological characteristics, induced significantly better protection against challenge with the Inaba strain than with the Ogawa strain. The MAR indices recorded for the non-toxigenic strain JBK70 were significantly lower than those of the parent strain N16961 ( $p<0.01$ in both instances). In contrast, significant differences between the protec- 
Table II. Antibodies in serum and intestinal mucus of rats immunised with live bacteria of $V$. cholerae strain 569B

\begin{tabular}{|c|c|c|c|c|c|c|}
\hline \multirow{3}{*}{$\begin{array}{l}\text { Number of } \\
\text { immunising } \\
\text { doses }\end{array}$} & \multirow{3}{*}{$\begin{array}{c}\text { Weeks after last } \\
\text { injection }\end{array}$} & \multirow{3}{*}{$\begin{array}{c}\text { Mean serum } \\
\text { vibriocidal } \\
\text { antibody titre* }\end{array}$} & \multicolumn{4}{|c|}{$\begin{array}{l}\text { Antibody concentrations } \dagger \\
\text { in intestinal mucus }\end{array}$} \\
\hline & & & \multicolumn{2}{|c|}{ anti-LPS } & \multicolumn{2}{|c|}{ anti-HSSP } \\
\hline & & & $\operatorname{IgA}$ & $\mathrm{IgG}$ & $\operatorname{IgA}$ & IgG \\
\hline \multirow[t]{5}{*}{1} & 1 & $3 \cdot 7(4 \cdot 3) \ddagger$ & $0(0) \ddagger$ & $0(0)$ & $0(0)$ & $0(0)$ \\
\hline & 2 & $3.0(3 \cdot 7)$ & $0(0)^{+}$ & $0(0)$ & $0(0)$ & $0(0)$ \\
\hline & 4 & $4 \cdot 0(3 \cdot 9)$ & $0(0)$ & $0(0)$ & $0(0)$ & $0(0)$ \\
\hline & 12 & $2 \cdot 3(2 \cdot 8)$ & $0(0)$ & $0(0)$ & $0(0)$ & $0(0)$ \\
\hline & 20 & $2 \cdot 1(2 \cdot 2)$ & $0(0)$ & $0(0)$ & $0(0)$ & $0(0)$ \\
\hline \multirow[t]{3}{*}{2} & 1 & $6 \cdot 5(7 \cdot 3)$ & $++(+)$ & $++(++)$ & $+(+)$ & $+(+)$ \\
\hline & 12 & $2 \cdot 5(2 \cdot 5)$ & $+(0)$ & $++(++)$ & $0(0)$ & $0(0)$ \\
\hline & 20 & $2.5(2.5)$ & $++(0)$ & $+++(0)$ & $0(0)$ & $0(0)$ \\
\hline
\end{tabular}

* In $\log _{10}$ units; the range of titres in non-immunised rats was $1 \cdot 7-2 \cdot 0$.

$\dagger$ Expressed as increases in titre, by the ELISA method, above those of non-immunised rats tested at the same time : $0=<4$-fold; $+=4$-8-fold $;+=8$-32-fold; and $+++=>32$-fold.

$\ddagger$ Each set of results was obtained after i.i. (or i.v.) immunisation of groups of 8 rats.

Table III. Mucosa-association resistance and serum vibriocidal antibody titres in rats four weeks after immunisation with one i.i. dose of $c .1 \times 10^{9} \mathrm{cfu}$ of strains of $V$. cholerae

\begin{tabular}{|c|c|c|c|c|c|}
\hline \multicolumn{2}{|c|}{ Immunising strain of $V$. cholerae } & \multirow{2}{*}{$\begin{array}{c}\text { Mean serum } \\
\text { vibriocidal } \\
\text { antibody titre* }\end{array}$} & \multicolumn{2}{|c|}{$\begin{array}{l}\text { MAR indices* in rats } \\
\text { challenged with }\end{array}$} & \multirow[b]{2}{*}{ p values } \\
\hline $\begin{array}{c}\text { Strain } \\
\text { no. } †\end{array}$ & $\begin{array}{l}\text { Biotype, } \\
\text { serotype }\end{array}$ & & $\begin{array}{c}\text { Inaba strain } \\
\text { BRL7738 }\end{array}$ & $\begin{array}{c}\text { Ogawa strain } \\
0162\end{array}$ & \\
\hline BRL7738 & El Tor, Inaba & $3 \cdot 9$ & $4 \cdot 25$ & $2 \cdot 12$ & $<0.001$ \\
\hline N16961 & El Tor, Inaba & $4 \cdot 2$ & $3 \cdot 80$ & $3 \cdot 37$ & $>0.05$ \\
\hline JBK 70 & El Tor, Inaba & $3 \cdot 5$ & $2 \cdot 82$ & $1 \cdot 64$ & $<0.05$ \\
\hline CVD107§ & El Tor, Inaba & $3 \cdot 2$ & $3 \cdot 67$ & $2 \cdot 67$ & $<0.05$ \\
\hline $569 B$ & Classical, Inaba & $3 \cdot 9$ & $3 \cdot 91$ & $2 \cdot 94$ & $<0.01$ \\
\hline CVD103‡ & Classical, Inaba & $2 \cdot 9$ & $2 \cdot 86$ & $2 \cdot 16$ & $>0 \cdot 30$ \\
\hline 35A3 & Classical, Inaba & 3.4 & $4 \cdot 13$ & $3 \cdot 25$ & $<0.05$ \\
\hline VB1961 & El Tor, Ogawa & $3 \cdot 2$ & $3 \cdot 08$ & $3 \cdot 84$ & $>0 \cdot 1$ \\
\hline 0162 & Classical, Ogawa & $3 \cdot 0$ & $2 \cdot 73$ & $4 \cdot 09$ & $<0.001$ \\
\hline 3083 & Classical, Ogawa & $2 \cdot 8$ & $2 \cdot 48$ & $4 \cdot 46$ & $<0.001$ \\
\hline "Texas Star" $\ddagger$ & Classical, Ogawa & $3 \cdot 5$ & $2 \cdot 07$ & $3 \cdot 24$ & $<0.01$ \\
\hline $111-V 58$ & Classical, Ogawa & $3 \cdot 6$ & $1 \cdot 29$ & $2 \cdot 82$ & $<0.01$ \\
\hline $111-V 58 \mathrm{NM}$ & Classical, Ogawa & $2 \cdot 6$ & $2 \cdot 18$ & $3 \cdot 19$ & $<0.05$ \\
\hline KB112NM\| & Classical, Ogawa & $2 \cdot 3$ & $1 \cdot 19$ & 3.93 & $<0.001$ \\
\hline NW35 & Classical, Hikojima & $3 \cdot 3$ & $4 \cdot 64$ & $2 \cdot 63$ & $<0.001$ \\
\hline
\end{tabular}

* Vibriocidal antibody titres expressed and determined as in table II with groups of 8 rats. MAR indices shown here are the means of 24 replicates obtained from the formula $\mathrm{C}-\mathrm{I}$ where $\mathrm{C}=\operatorname{mean}_{\log } \mathrm{cfu}$ of mucosa-associated organisms in 24 loops in non-immunised rats and $I=\log _{10}$ cfu of mucosaassociated organisms in each of 24 loops in immunised rats; control and immunised rats were tested at the same time. C values for rats challenged with strains BRL7738 and O162 were not significantly different in each of the above tests.

$\dagger$ Strains 3083, Texas Star, N16961, CVD107 and CVD103 were obtained from Dr J. Kaper, Center for Vaccine Development, University of Maryland, USA. Other strains were from the culture collection of the School of Microbiology, NSW, Australia.

¥ The non-toxigenic mutant strains JBK70, CVD103 and Texas Star were derived from strains N16961, 569B and 3083, respectively.

$\S$ The non-motile strain CVD107 (with paralysed flagella) was derived from strain N16961.

|| The non-motile, non-flagellate strains 111-V58NM and KB112NM were derived from strain 111V58. 
tive capacity of the parent strains 569B and 3083 and their respective non-toxigenic mutant strains CVD103 and "Texas Star" occurred following challenge with the homologous serotype only ( $\mathrm{p}<$ 0.05 and $<0.001$, respectively). Non-motile strains of $V$. cholerae were also protective; the MAR indices were not significantly different from those recorded with the two parent strains available for testing ( $p>0.3$ for each). Though not shown in the table, antibodies were not found in the intestinal mucus of similarly immunised rats examined at the time of challenge. However, relatively low levels of serum vibriocidal activity were present in all immunised groups irrespective of immunity to the mucosal infection.

\section{Protective activity of LPS antigen}

The protection provided by LPS was investigated by injecting Inaba LPS in Freund's adjuvant by the i.p.p. route. Serum and intestinal mucus antibody levels at the time of challenge were determined in separate groups of rats. For comparative purposes, other rats were immunised i.p.p. with live organisms of the Inaba strain 569B. Though LPS was immunogenic and protective, these properties were evident only after two injections of antigen. In contrast, one injection of live organisms by the same route protected animals challenged 4 weeks later, even though anti-LPS antibodies were not detected in serum or intestinal mucus at that time (table IV).

\section{Characteristics of $V$. cholerae $O M P s$}

SDS-PAGE profiles of OMPs derived from several $V$. cholerae strains are shown in fig. 1 . The major protein bands had mol. wts $\left(10^{3}\right)$ in the region 42-45; at least 15 other bands were resolved. Profiles of all strains of $V$. cholerae tested were generally similar and quite distinct from those of the strain of $P$. aeruginosa tested; some similarity with the profile of a representative strain of $C$. jejuni was noted.

When monomeric sub-units were separated by hydrophobic-interaction HPLC, six peaks with common retention times were found with all OMPs of $V$. cholerae tested. With different strains, however, the relative abundance of proteins isolated at each retention time varied; when results for strains of one serotype were pooled, statistical consistency for each of the protein peaks was found. Moreover, the profiles for the two common serotypes were readily distinguished whereas that of the only strain (NW35) of Hikojima serotype tested was similar to that of strains of Inaba serotype (fig. 2).

\section{Protection by $O M P$ preparations}

Results of experiments in which rats were immunised by the i.p.p. route with OMP preparations are summarised in table V. Antibody levels in serum and intestinal mucus were determined in separate groups at the time of challenge. OMP from the challenge strain BRL7738 protected against mucosal association; however, it induced both antiHSSP and anti-LPS antibodies in serum and intestinal mucus. Results of immunoblotting studies (fig. 3) suggested that the latter responses were most likely due to LPS associated with a number of proteins detected by SDS-PAGE, including those of mol.wt (42-45) $\times 10^{3}$. OMP from the rough strain NW31, on the other hand, showed little reaction

Table IV. Immunity to mucosal association induced in rats by i.p.p. injection of LPS antigen from $V$. cholerae strain 569B of Inaba serotype

\begin{tabular}{|c|c|c|c|c|c|c|c|}
\hline \multirow[b]{3}{*}{ Antigen } & \multirow{3}{*}{$\begin{array}{c}\text { Number of } \\
\text { doses }\end{array}$} & \multirow{3}{*}{$\begin{array}{l}\text { Day of challenge } \\
\text { after last } \\
\text { immunising dose }\end{array}$} & \multicolumn{4}{|c|}{ Mean anti-LPS antibody concentrations* in } & \multirow{3}{*}{$\begin{array}{c}\text { MAR } \\
\text { index* }\end{array}$} \\
\hline & & & \multicolumn{2}{|c|}{ serum } & \multicolumn{2}{|c|}{ intestinal mucus } & \\
\hline & & & $\operatorname{IgM}$ & $\mathrm{IgG}$ & $\operatorname{Ig} A$ & IgG & \\
\hline LPS & 1 & 28 & 0 & 0 & 0 & 0 & $1.86(\mathrm{NS})$ \\
\hline L-O & 1 & 28 & 0 & 0 & $\mathbf{0}$ & 0 & $3.32(\mathrm{~S})$ \\
\hline LPS & 2 & 5 & +++ & ++ & + & + & $3.75(\mathrm{~S})$ \\
\hline L-O & 2 & 5 & ++ & + & 0 & + & $4 \cdot 58(\mathrm{~S})$ \\
\hline
\end{tabular}

\footnotetext{
* See footnotes, tables I and II.

LPS $=$ Lipopolysaccharide ( $150 \mu \mathrm{g}$ in Freund's adjuvant given in each dose).

LO $=$ Live organisms $\left(4 \times 10^{8}\right.$ cfu of $V$. cholerae strain $569 \mathrm{~B}$ given in each dose).

$\mathrm{S}=$ significant; and NS = not significant.
} 


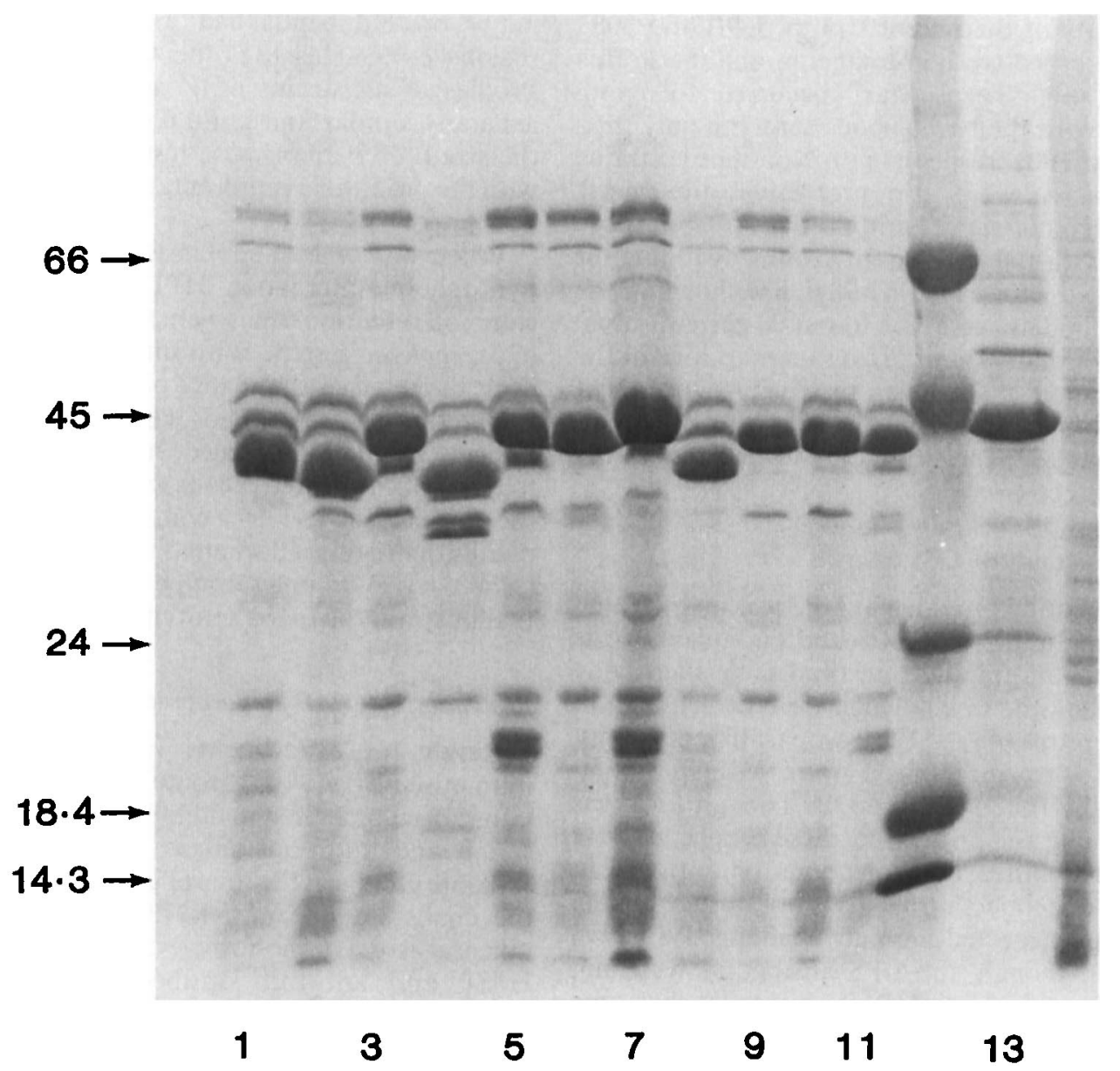

Fig. 1 SDS-PAGE of OMPs derived from $V$. cholerae. The strains tested in lanes $1-11$ were: (1) 35A3; (2) BRL7738; (3) O162; (4) NW35; (5) 569B; (6) KB112NM; (7) 569B; (8) 35A3; (9) 111-V58NM; (10) 111-V58; and (11) N16961. Lane 12 contains mol.-wt $\left(10^{3}\right)$ standards as shown on the left. OMPs of $C$. jejuni and $P$. aeruginosa strain NSW467 are shown in lanes 13 and 14 , respectively.

with these antibodies, although it shared two of the three major immunogenic proteins of the strain BRL7738. Responses to HSSP, but not LPS, following injections with the OMP of strain NW31 were consistent with these observations, but this material did not induce resistance to mucosal colonisation.

\section{Discussion}

The rat intestinal loop model provides a measure of active immunity to cholera infection; it reflects the ability of immunised animals to restrict the association of the causative agent with, or proliferation at, the intestinal surfaces. As with other recently described models (e.g., Spira et al., 1981; Tokunaga et al., 1984), it permits assessment of the protective capacity of live cholera vaccines or other antigenic preparations and does not rely on indirect evidence obtained from passive-immunisation studies made in vivo (e.g., Ujiiye and Kobari, 1970) or in vitro (e.g., Attridge and Rowley, 1983).

Effective immunity was induced by live organisms given locally or parenterally and was retained for periods of $>10$ weeks after one or two immunising doses but, as with most immune responses, its onset was more rapid and its duration longer when two immunising doses were used. Results from volunteer studies have suggested that long-term resistance to cholera following clinical or sub-clinical infection may exist in the absence of antibodies other than those responsible for serum vibriocidal activity (Cash et al., 1974). It is possible that the rat infection model used 4 weeks after a 


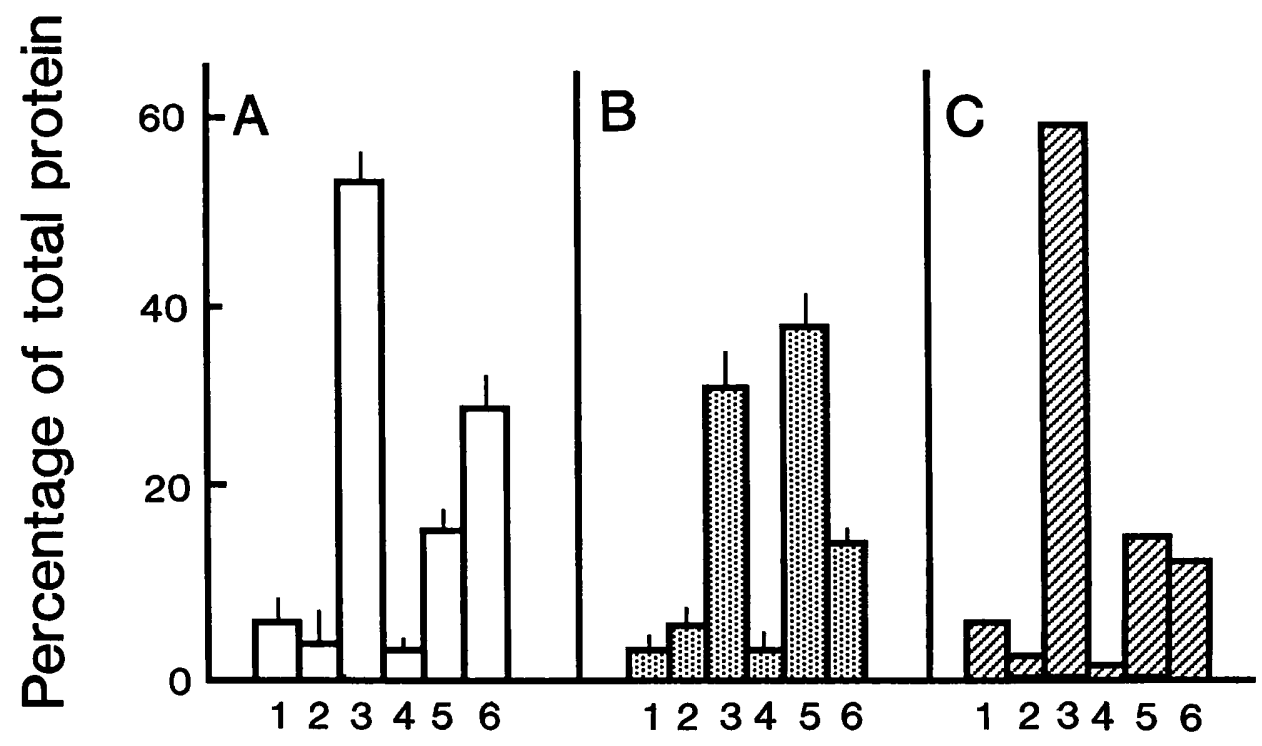

\section{Peak number}

Fig. 2 HPLC fractionation of OMP preparations on $\mu$-Bondapak C18 columns. Comparison of "relative abundance of protein" profiles were obtained from the means of results recorded for: (A) V. cholerae Inaba strains 35A3, BRL7738, 569B, N16961 ; (B) V. cholerae Ogawa strains VB1961, O162, 3083, 111-V58, KB112NM; (C) V. cholerae Hikojima strain NW35. Error bars, where appropriate, are shown. Retention times (min) for the peaks were: $1 \cdot 2(1) ; 1 \cdot 7(2) ; 2 \cdot 8(3) ; 12(4) ; 15(5) ;$ and $19(6)$.

single dose of organisms or antigen, i.e., when the same serological results are found, offers an opportunity to study the nature of this immunity and methods for its induction.

Despite evidence from earlier findings (Cooper and Narendranathan, 1986), correlations between resistance to mucosal association and antibody levels must now be questioned. As in man (Clements et al., 1982), live organisms in the rat intestine leave a long-term legacy of low levels of serum vibriocidal activity. Association of this activity with resistance may be no more than fortuitous. For instance, 7 days after one dose of organisms, rats were no more resistant than non-immunised animals despite high titres of serum vibriocidal antibody. Again, though resistance and the presence of anti-LPS antibodies in intestinal mucus after two immunising doses were seemingly related, these antibodies were not found in resistant animals that received only one dose of organisms. These and related findings (tables I and II) suggested that serological tests of serum or intestinal materials were unlikely to

Table V. Immunising activity of outer-membrane proteins prepared from strains of $V$. cholerae

\begin{tabular}{|c|c|c|c|c|c|c|c|c|c|}
\hline \multirow{3}{*}{$\begin{array}{l}\text { OMP from } \\
\text { strain no. }\end{array}$} & \multicolumn{4}{|c|}{ Anti-LPS antibodies* in } & \multicolumn{4}{|c|}{ Anti-HSSP* antibodies in } & \multirow{3}{*}{$\begin{array}{c}\text { MAR } \\
\text { index* }\end{array}$} \\
\hline & \multicolumn{2}{|c|}{ serum } & \multicolumn{2}{|c|}{ intestinal mucus } & \multicolumn{2}{|c|}{ serum } & \multicolumn{2}{|c|}{ intestinal mucus } & \\
\hline & IgM & IgG & IgA & IgG & IgM & IgG & $\operatorname{IgA}$ & $\mathrm{IgG}$ & \\
\hline $\begin{array}{l}\text { BRL7738 } \\
\text { NW31 } \\
\text { NSW467† }\end{array}$ & $\begin{array}{c}+++ \\
0 \\
0\end{array}$ & $\begin{array}{c}++ \\
0 \\
0\end{array}$ & $\begin{array}{c}++ \\
0 \\
0\end{array}$ & $\begin{array}{c}+++ \\
0 \\
0\end{array}$ & $\begin{array}{c}0 \\
++ \\
0\end{array}$ & $\begin{array}{c}++ \\
+ \\
0\end{array}$ & $\begin{array}{c}+++ \\
++ \\
0\end{array}$ & $\begin{array}{c}+++ \\
++ \\
0\end{array}$ & $\begin{array}{l}3.95 \text { (S) } \\
0.23 \text { (NS) } \\
0.11 \text { (NS) }\end{array}$ \\
\hline
\end{tabular}

* See footnotes, tables I and II. The Inaba strain BRL7738 was used as the challenge strain, 5 days after two i.p.p. injections of OMP (150 $\mu \mathrm{g}$ in Freund's adjuvant) given 14 days apart; antibody titres were determined at the same time. $\dagger P$. aeruginosa strain NSW467 was included as a negative control. 


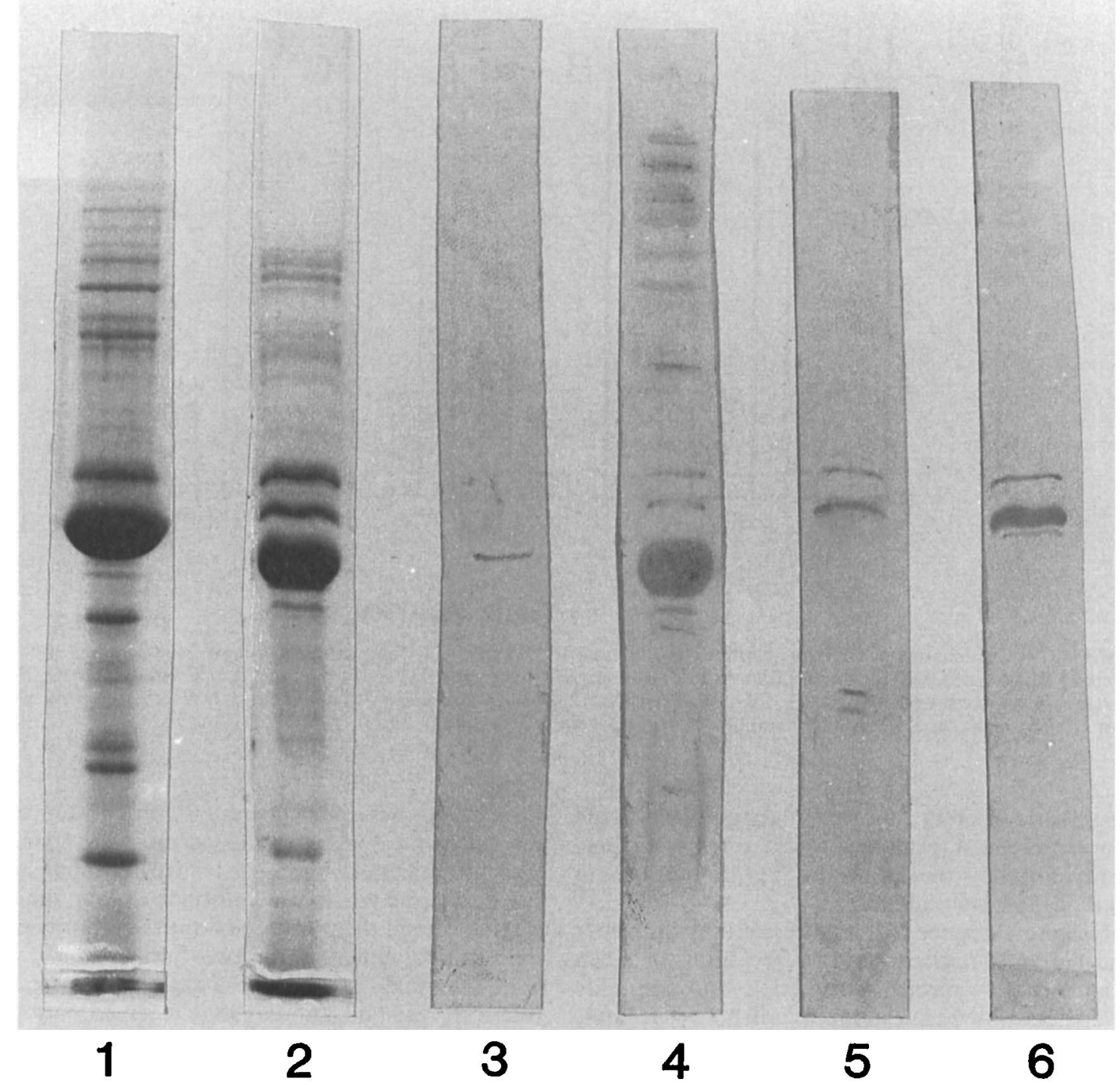

Fig. 3 SDS-PAGE (lanes 1,2) and immunoblotting (lanes 3-6) of OMPs derived from strains of $V$. cholerae. The rough mutant strain NW31 derived from Ogawa strain O162 is shown in lanes 1, 3 and 5: the strain BRL7738 of serotype Inaba is shown in lanes 2,4 and 6. For the immunoblots, rabbit anti-LPS antiserum (lanes 3 and 4) or rabbit antiserum prepared against strain BRL7738, and absorbed with Inaba LPS (lanes 5 and 6) were used.

provide direct indication of immune status to the disease.

Indications from previous studies that the cellwall LPS of $V$. cholerae is a protective antigen (e.g., Holmgren and Svennerholm, 1983) have been confirmed. These results and those of earlier studies (Cooper and Narendranathan, 1986), suggest that resistance to mucosal association induced by LPS depends on continued output of anti-LPS antibodies into the intestine via the mucosal surfaces and, perhaps, bile also (Cooper et al., 1984). Although the present results do not seem to implicate LPS in the induction of immunity to mucosal colonisation, failure to detect anti-LPS antibodies does not exclude their involvement; furthermore, absence of protective activity after a single injection of LPS could merely reflect poorer immunogenicity of the extracted material compared with the form in which it is presented in the intact organism. Nonetheless, attention is drawn to a second tier of immunity in which antigens other than LPS may be involved (Attridge and Rowley, 1983); the most 
likely candidates are the heat-sensitive proteins of the organism's outer membranes.

As reported by others (e.g., Kabir, 1983; Sears et al., 1984), SDS-PAGE separation and immunoblotting indicated that there were physico-chemical and serological similarities among the major monomeric sub-units of OMPs prepared from strains of the common serotypes of $V$. cholerae. Furthermore, it is obvious that LPS association with a number of these proteins precludes direct assessment of their protective capacity. The device of using an OMP prepared from a rough strain of $V$. cholerae has produced results that call into question the involvement of these antigens in resistance in the rat model. Even though the OMP derived from the rough strain contained at least two of the major immunogenic proteins associated with the surfaces of a protective strain (BRL78738) and, when injected into the Peyer's patches, caused output into the intestine of antibodies that reacted specifically with those antigens, it was no more protective than a preparation obtained from the serologically unrelated strain of $P$. aeruginosa. This result also suggested that the adjuvant itself did not enhance immunity by non-specific means. Loss of putatively protective proteins from the rough strain cannot be discounted but, if OMPs are involved in resistance to mucosa association, present serological methods seem to be either too insensitive or insufficiently discriminatory to detect them.

Whilst cross resistance was expressed in the absence of antibodies other than those causing serum vibriocidal activity, the level of resistance was significantly higher when serotypic homology existed between immunising and challenge strains. This is consistent with results from field trials with monovalent killed vaccines (Mosley et al., 1973) and animal-immunisation experiments (Svennerholm et al., 1975). Though the latter workers implicated type-specific antigenic determinants of LPS, absence of anti-LPS antibodies in immune rats is against this hypothesis. Until now, incrimination of the protein antigens of $V$. cholerae has not been justified because of many similarities among the OMPs obtained from different $V$. cholerae strains. Hydrophobic interaction HPLC techniques, however, have revealed for the first time

\section{REFERENCES}

Attridge S R, Rowley D 1983 Prophylactic significance of the nonlipolysaccharide antigens of Vibrio cholerae. Journal of Infectious Diseases 148: 931-939.

Auzins I 1968 A comparative assay of O-somatic antigen 5 of salmonellae. Australian Journal of Experimental Biology and Medical Science 46: 93-105. that serotype-associated differences do exist in these materials. In the absence of effective preparative methods with this separation technique, chemical and serological differences cannot be excluded but similarities of retention times of the six major proteins suggest that the differences are more likely to be quantitative. Nevertheless, they may be sufficient to account for the better performance of serotypically homologous strains in protection tests. It was interesting to find that strains of Hikojima serotype induced significantly better resistance to Inaba challenge than did Ogawa strains; the Hikojima strain also had an HPLC profile similar to that of Inaba strains.

Local immunisation by intestinal injection of live organisms has confirmed findings of Tokunaga $e t$ al. (1984) that the mutant strain "Texas Star" is less protective than the parent strain 3083 ; this is also true for the non-toxigenic mutant strain JBK70 derived from strain N16961. Whereas poorer protection has been attributed to loss of colonising and, hence, immunising ability (Tokunaga et al., 1984), similarity of serum vibriocidal antibody titres in rats given parent or mutant strains suggests that this may not be so. Again, because a poorly colonising non-motile mutant strain was equally as protective as the parent strain N16961, loss of toxigenicity may be more important in reducing protective activity.

Finally, it was interesting to find that nonflagellate strains were protective. Although both non-flagellate strains colonised the rat intestine surface poorly (Cooper and Narendranathan, 1986), it was clear that their immunogenicity was not thereby affected. Passive-protection tests (Eubanks et al., 1977) have implicated flagella-associated antigens in protection against cholera infection. The present results, currently being extended with non-motile strains derived from other isolates of $V$. cholerae, must question the validity of that hypothesis. Use of the rat model may resolve this and other questions relating to antibacterial immunity in cholera.

This work was supported by a grant from the National Health and Medical Research Council of Australia. The assistance of Ms Janet Sharp and Ms Pat Walker has been greatly appreciated.

Cash R A, Music S I, Libonati J P, Craig J P, Pierce N F, Hornick R B 1974 Response of man to infection with Vibrio cholerae. II Protection from illness afforded by previous disease and vaccine. Journal of Infectious Diseases 130: 325333.

Clements M L et al. 1982 Magnitude, kinetics and duration of vibriocidal antibody responses in North Americans after 
ingestion of Vibrio cholerae. Journal of Infectious Diseases 145: $465-473$.

Cooper G N, Jackson G D F 1981 Immune responses of rats to live Vibrio cholerae: antibodies in serum and intestinal secretions. Parasite Immunology 3: 57-68.

Cooper G N, McNab C E, Walker P G, Jackson G D F 1984 Intestinal antibodies in rats following exposure to live Vibrio cholerae. Australian Journal of Experimental Biology and Medical Science 62: 465-477.

Cooper G N, Narendranathan R 1986 Antibacterial immunity to Vibrio cholerae in rats. Journal of Medical Microbiology 22: 133-141.

Eubanks E R, Guentzel M N, Berry L J 1977 Evaluation of surface components of Vibrio cholerae as protective immunogens. Infection and Immunity 15: 533-538.

Hawkes R, Niday E, Gordon J 1982 A dot-immunobinding assay for monoclonal and other antibodies. Analytical Biochemistry 119: 142-147.

Holmgren J, Svennerholm A-M 1983 Cholera and the immune response. Progress in Allergy 33: 106-119.

Kabir S 1983 The serological properties of the cell surface proteins of Vibrio cholerae. Journal of General Microbiology 129: 2199-2206.

Laemmli U K 1970 Cleavage of structural proteins during the assembly of the head of bacteriophage T4. Nature 227:680685.

Levine M M et al. 1979 Immunity of cholera in man: relative role of antibacterial versus antitoxic immunity. Transactions of the Society of Tropical Medicine and Hygiene 73: 3-9.

Mosley W H, Aziz K M A, Rahman A S M M, Chowdhury A K M A, Ahmed A 1973 Field trials of monovalent Ogawa and Inaba cholera vaccines in rural Bangladesh: three years of observation. Bulletin of the World Health Organization 49: $381-387$.
Schaedler R W, Dubos R, Costello R 1965 The development of the bacterial flora in the gastrointestinal tract of mice. Journal of Experimental Medicine 122: 59-66.

Schnaitman C A 1971 Solubilization of the cytoplasmic membrane of Escherichia coli by Triton X-100. Journal of Bacteriology 108: 545-552.

Sears S D, Richardson K, Young C, Parker C D, Levine M M 1984 Evaluation of the human immune response to outer membrane proteins of Vibrio cholerae. Infection and Immunity 44: 439-444.

Spira W M, Sack R B, Froehlich J L 1981 Simple adult rabbit model for Vibrio cholerae and enterotoxigenic Escherichia coli diarrhea. Infection and Immunity 32: 739-747.

Svennerholm A-M, Holmgren J, Ouchterlony O 1975 Experimental studies on cholera immunisation. V. Cross reactive and type specific determinants on $V$. cholerae Inaba and Ogawa endotoxin and their significance for protective immunity. Acta Pathologica et Microbiologica Scandinavica Section C 83: 221-230.

Tokunaga E, Cray W C, Pierce N F 1984 Compared colonizing and immunizing efficiency of toxinogenic $\left(\mathrm{A}^{+} \mathrm{B}^{+}\right)$Vibrio cholerae and an $\mathrm{A}^{-} \mathrm{B}^{+}$mutant (Texas Star-SR) studied in adult rabbits. Infection and Immunity 44: 364-369.

Towbin H, Staehelin T, Gordon J 1979 Electrophoretic transfer of proteins from polyacrylamide gels to nitrocellulose sheets: procedure and some applications. Proceedings of the National Academy of Sciences of the USA 76: 4350-4354.

Ujiiye A, Kobari K 1970 Protective effect on infections with Vibrio cholerae in suckling mice caused by the passive immunization with milk of immune mothers. Journal of Infectious Diseases 121 Suppl: s50-s55.

Westphal O, Jann K 1965 Bacterial lipopolysaccharides. Extraction with phenol-water and further applications of the procedure. In: Whistler R L (ed) Methods in carbohydrate chemistry Academic Press Inc., New York 5: 83-91. 